\title{
Ekaterina Makhotina
}

\section{Die Nähe Smetonas}

Nationale Identitätskonstruktion und Demokratie in Litauen

Die Litauische Republik, die vor hundert Jahren im Zuge des Zerfalls der Imperien im Ersten Weltkrieg gegründet wurde, wies eine vorbildliche demokratische Verfassung auf. Jedoch hatte diese nicht lange Bestand. Von allen drei baltischen Republiken bestand die Demokratie in Litauen am kürzesten: Mit dem Militärputsch von 1926 wurde in Litauen eine autoritäre Diktatur, unter Antanas Smetona als nationalem Anführer an der Spitze errichtet.

Im heutigen Litauen, seit 2004 Mitglied der Europäischen Union, scheint vor allem die unter Smetona von 1926 bis 1940 entwickelte historische Meistererzählung aktuell zu sein - zum Ausdruck kommt dies in einer geschichtspolitisch gestützten ethno-nationalisierenden Perspektive auf die „tausendjährige Geschichte“ Litauens und in der „Suche nach Litauen in der litauischen Geschichte“. Nach einer kurze Skizze der Etablierung des autoritären Systems nimmt der folgende Beitrag daher insbesondere die Entstehung des historischen Selbstbilds Litauens in den Blick und fragt nach Kontinuität und Kontingenz im Aufbau des nationalen Gedächtnisses von der Smetona-Zeit bis heute. Wie aktuell ist die autoritäre Diktatur von 1926 bis 1940 für das historische Selbstbild Litauens und für die Konstruktion der nationalen Identität? Wie viel Gewicht wird dem Erbe der Demokratie, wie viel der Nationalgeschichte beigemessen?

\section{Der Weg in die Unabhängigkeit}

Der Erste Weltkrieg und die Russische Revolution bildeten wichtige Voraussetzungen für die Gründung des unabhängigen litauischen Staats 1918. ${ }^{1}$ Als kaiserliche Truppen das litauische Gebiet im September 1915 besetzten, verlagerte sich die Debatte der litauischen Intellektuellen über die nationale Zukunft nach Russland. Die zentralrussische Stadt Voronež wurde zum Zentrum der Debatten der litauischen Kriegsgeflüchteten über die nationale Zukunft. ${ }^{2}$ Hier diskutierte die in Kreisen der russischen Studentenschaft politisierte litauische Intelligenzija und es entstand ein breites Spektrum politischer Parteien, von den Sozialdemokraten bis hin zu den Konservativen. ${ }^{3}$ Die intellektuelle Entwicklung der Idee der nationalen Unabhängigkeit war also eng mit dem revolutionären Geschehen in Russland verwoben. Vor allem die Februarrevolution 1917 in Russland stellte einen Wendepunkt für die Mobilisierung der Unabhängigkeitsbestrebungen litau-

\footnotetext{
${ }^{1}$ Vgl. Zigmantas Kiaupa, The History of Lithuania, Vilnius ${ }^{2}$ 2005. Der vorliegende Beitrag wurde gefördert von der Russländischen Wissenschaftstiftung (Rossijskij Naučnyj Fond, RNF) No. 17-18-01589.

${ }^{2}$ Vgl. Tomas Balkelis, The Making of Modern Lithuania, Abingdon 2009, S. 107.

${ }^{3}$ Vgl. ebenda, S. 105. In Voronež nahmen an den hitzigen Debatten die drei wichtigsten Männer der neueren litauischen Geschichte teil: Antanas Sniečkus, Antanas Smetona und Jonas Basanavičius.
} 
ischer intellektueller Eliten dar. ${ }^{4}$ Die politische Vision der nationalen Bewegung bestand zunächst in der territorialen Autonomie und später, nach den russischen Revolutionen, im Nationalstaat mit den Litauern als dominierender Gruppe. ${ }^{5}$ Das Verständnis der litauischen Nation (Tauta) war ein ethnolinguistisches: Das neue Litauen sollte Gebiete umfassen, in denen die litauische Sprache dominierte. Wie Smetona - damals nationaler Denker, später Präsident und Diktator - 1912 formulierte, sollten sich die Grenzen Litauens so weit erstrecken, „wie die lebenden Zeichen unserer Sprache reichen“ ${ }^{6}$

Im Vorgehen der deutschen Besatzungsmacht konnte man von 1915 bis 1917 zunächst keine logische Strategie erkennen: das Schicksal Litauens war zwischen der politischen und militärischen Führung umstritten. ${ }^{7}$ Für die deutsche Militärführung waren die baltischen Staaten nicht mehr als Handelsobjekte beim Bemühen um einen Sonderfrieden mit Russland. Da der Abschluss nicht zustande kam, sollten die eroberten Gebiete von Russland abgetrennt und mit dem Scheinstatus unabhängiger Staaten an Deutschland gebunden werden. ${ }^{8}$ Die Forderungen des von Smetona angeführten Rats (Taryba) im September 1917 nach der Erweiterung der politischen Befugnisse der Litauer - politische Autonomie in den ethnografischen Grenzen inklusive der Hauptstadt Vilnius - ließ die deutsche Militärführung nicht gelten. Nach der Oktoberrevolution in Petrograd und in der Situation des faktischen Rückzugs Russlands aus dem Krieg erklärte Taryba am 16. Februar 1918 die Unabhängigkeit Litauens. Diese blieb wegen der Präsenz der deutschen Militärs im Lande und der Anbindung an Deutschland durch zahlreiche Abkommen sowie der „Wahl“ von Wilhelm Karl von Urach zum König „Mindaugas II.“ nominell - bis zum Waffenstillstand von Compiegne. Ende 1918 bestärkte Litauen die nationale Unabhängigkeit durch das Zusammenkommen des ersten litauischen Regierungskabinetts und die Gründung der litauischen Armee. Nach dem Rückzug der Alliierten aus dem russischen Bürgerkrieg - diese unterstützten die „weißen“ antibolschewistischen Kräfte mit ihrer Orientierung am „heiligen unteilbaren Russland“ - schien der Triumph der Solidarität nah zu sein, hätte nicht 1920 die polnische Armee des Generals Lucjan Żeligowski Wilno (Vilnius) besetzt und 1922 nach einem Plebiszit an Polen angeschlossen. Die Auseinandersetzung um das Wilno-Gebiet zwischen Polen und Litauern im Kontext des sowjetrussischpolnischen Kriegs wird in der litauischen Historiografie als „Kriege für die Unabhängigkeit“ bezeichnet. ${ }^{9}$ Die Bedeutung von Vilnius, das dem Zensus von 1897

\footnotetext{
${ }^{4}$ Vgl. ebenda, S. 21.

${ }^{5}$ Vgl. Vladas Sirutavičius/Darius Staliunas, Introduction, in: Vladas Sirutavičius/Darius Staliunas (Hrsg.), A Pragmatic Alliance. Jewish-Lithuanian Political Cooperation at the Beginning of the 20th Century, Budapest, S. 1-18, hier S. 2.

${ }^{6}$ Zit. nach ebenda, S. 2.

${ }^{7}$ Vgl. Sigmar Stopinski, Das Baltikum im Patt der Mächte. Zur Entstehung Estlands, Lettlands und Litauens im Gefolge des Ersten Weltkriegs, Berlin 1997, S. 83-102.

${ }^{8}$ Vgl. ebenda, S. 255.

${ }^{9}$ Vgl. Mindaugas Šapoka, Millennium of Lithuania. Lietuva 1009-2009, Vilnius 2009, S.77.
} 
zufolge nur zwei Prozent litauische Bewohner hatte, ${ }^{10}$ lag in der starken symbolischen Aufladung als nationaler Erinnerungsort. Es sollte die historische Kontinuität zwischen dem Großfürstentum Litauen und dem modernen Litauen symbolisieren. Der Status von Vilnius als litauischer Hauptstadt liegt in der klassischen Sage zur Stadtentstehung begründet: Hier soll der mittelalterliche Herrscher Gediminas, der Staatsgründer, von einem unverwundbaren Wolf geträumt und daraufhin die Errichtung der Burg beschlossen haben. Von daher erhält das Argument der historischen Zugehörigkeit von Vilnius zu Litauen die zentrale Rolle in der nationalen Propaganda und beeinflusst wesentlich die Politik gegenüber der polnischen ethnischen Gruppe.

Zunächst zeichnete sich das auf der 1922 erlassenen Verfassung basierende politische Leben Litauens, wie das aller drei baltischen Republiken, durch Demokratie und Parteienvielfalt aus. Hier konkurrierten Sozialdemokraten, Kommunisten, Bauern-Volkstümler, Christliche Demokraten und Nationalisten (Tautininkai) um die politische Führung, wobei die letzteren am wenigsten $\mathrm{Zu}$ spruch erhielten.

Nach der internationalen Anerkennung von Vilnius als polnischer Stadt 1923 wurden langsam Veränderungen in der Beziehung zu anderen Ethnien spürbar. Der Stellenwert der polnischen Kultur und Sprache in Litauen war ein Gradmesser für den kulturellen Liberalismus des jungen Staats. Seit 1923 wurde Litauen vom rechten Flügel (Christliche Demokraten) regiert, der für den Wandel der liberalen Politik gegenüber ethnischer Minderheiten eintrat. Der Propaganda der kulturellen Homogenisierung zufolge sollte so mit dem imperialen Erbe des russischen Vielvölkerstaats gebrochen werden. ${ }^{11}$

Es ist wenig überraschend, dass die junge und unerfahrene Demokratie nicht besonders stabil war: Die Regierungskabinette zeichneten sich durch ein hohes $\mathrm{Maß}$ an Instabilität aus, die Exekutive vor Ort litt an Schwächen, dazu kamen wirtschaftliche Schwierigkeiten. ${ }^{12}$ Als im Mai 1926 die linken Parteien Bauernunion und Sozialdemokraten die Regierung bildeten, putschte das Militär und brachte die zahlenmäßig kleine nationalistische Partei (Bund litauischer Nationalisten, Lietuvos Tautininku Sajunga, LTS) an die Macht.

\section{Von Demokratie zur Diktatur}

Der Militärputsch vom 17. Dezember 1926 wird oft als „Schicksalsereignis in der neueren Geschichte Litauens“ bezeichnet. ${ }^{13}$ Tatsächlich markiert dieser Tag das

\footnotetext{
${ }^{10}$ Vgl. Sirutavičius/Staliunas, Introduction, in: Sirutavičius/Staliunas (Hrsg.), Pragmatic Alliance, S. 4.

11 Vgl. Balkelis, Making, S. 117.

12 Vgl. Stanley Vardys, The Rise of Authoritarian Rule in the Baltic States, in: Ders./Romualdas Misiunas (Hrsg.), The Baltic States in Peace and War 1917-1945, State College 1978, S. 65-80, hier S. 67.

${ }^{13}$ Raimundas Lopata, Die Entstehung des autoritären Regimes in Litauen 1926. Umstände, Legitimation, Konzeption, in: Erwin Oberländer (Hrsg.), Autoritäre Regime in Ostmittel-
} 
Ende der siebenjährigen Demokratie in Litauen und demonstriert den Erfolg der demokratiefeindlichen Kräfte.

Die Ressentiments des Klerus, der Nationalgesinnten und des Offizierkorps gegen die vermeintliche „linke Politik“ (Säkularisierung der Eheschließung, Verminderung der Gehälter für die Geistlichen, Reduktion der Zahl der Offiziere, Toleranz gegenüber polnischen Schulen) bilden den Kontext für die nationalistische Antwort der Putschisten in Kaunas. Das Militär sah seine Rolle in der Politik in Gefahr, doch als Legitimation seines Vorgehens beschwor es die Gefahr der Bolschewisierung Litauens. ${ }^{14}$ Die bolschewistischen „Verräter“ wurden für alle Probleme in Litauen verantwortlich gemacht - von der politischen Instabilität bis zu wirtschaftlichen Schwierigkeiten. Als der Anführer der Putschisten, Povilas Plechavičius, den Präsidentenposten an Smetona übertrug, kam damit eine bislang eher unbedeutende Gruppe an die Macht ${ }^{15}$ - die Nationalisten, die durch verstärkte nationalistische Propaganda und das persönliche Charisma Smetonas ihre Legitimität zu begründen versuchten. ${ }^{16}$ Die demonstrative Abwehr der „drohenden bolschewistischen Gefahr“, gipfelte in der Hinrichtung von vier jungen Menschen, bekannten litauischen Kommunisten.

Bereits wenige Monate später verzichtete Smetona darauf, den demokratischen Schein zu wahren. Die Putschtaktik wurde als Regierungsstil fortgesetzt: Das Parlament, in dem zunächst die Nationalisten mit den Christlichen Demokraten koalierten, wurde aufgelöst. 1928 erließ Smetona eine neue Verfassung, die die präsidentielle Macht stärkte und eine deutliche Verschiebung in Richtung autoritäre Herrschaft markierte. Mittels dieser Taktik konnte er sich gegen die noch weiter rechts stehende, profaschistische Bewegung von Augustinas Voldemaras (Anführer des „Eisernen Wolfs“) behaupten. Die Voldermaras-Anhänger verloren an Bedeutung. Die Tautininku Sajunga, die Smetona-„Partei“, wurde nach dem Führerprinzip umgestaltet: Sie sollte eher eine Bewegung als eine Partei sein und die Vermittlerrolle zwischen „Volk“ und der präsidentiellen Administration spielen. ${ }^{17}$

Will man sich Smetonas Verständnis von Demokratie und Parlamentarismus nähern, so ist das folgende Zitat aufschlussreich:

„Parteien kämpfen in einem Parlament und ein Land verfällt in Anarchie, was schließlich mit der Diskreditierung der liberalen Administration endet. Diese Gefahr des Zusammenbruchs eines Lands und dass es einer kommunistischen Diktatur erliegt, hat eine entgegengerichtete soziale Bewegung hervorgerufen. Der Liberalismus, nicht der Sozialismus, hat diese Situation geschaffen und ist schuld

europa und Südosteuropa 1919-1940, 2., um ein Nachwort ergänzte Aufl., Paderborn 2017, S. 95-142, hier 139 .

${ }^{14}$ Vgl. Vardys, Rise, in: Ders./Misiunas (Hrsg.), Baltic States, S. 72, der diese These kritisch analysiert. Bei Alfonsas Eidintas u. a., Geschichte Litauens, Vilnius 2013, S. 174, ist es eher als eine apologetische Rechtfertigung des Putschs angeführt.

${ }^{15}$ Während der Parlamentswahlen 1926 erlangten die Nationalisten nur drei Sitze (von 85) im Parlament.

${ }^{16}$ Vgl. Lopata, Entstehung, in: Oberländer (Hrsg.), Autoritäre Regime, S. 140.

17 Vgl. Vardys, Rise, in: Ders./Misiunas (Hrsg.), Baltic States, S. 78. 
daran, dass Unordnung im Land aufgekommen ist. Und daher ist es wichtig die Parteienfreiheit einzuschränken." ${ }^{18}$

Seine Nationalistische Partei war eine wichtige Stütze des Regimes, setzte sie doch die Direktiven der Regierung um. Doch das System Smetona war keine Partei-, sondern eine patriarchalische, persönliche Diktatur nach dem Prinzip: ein Mann - ein Volk. ${ }^{19}$

1936 löste Smetona alle Parteien auf. Ihre Apotheose erreichte die autoritäre Herrschaft 1938, als er sich in der neuen Verfassung zum Oberbefehlshaber der Armee ernannte und alle Macht in den Händen des Präsidenten konzentriert wurde. Obwohl schon lange nicht mehr demokratisch, verlor nun die Litauische Republik auch in der Verfassung den Zusatz „demokratisch“.

\section{III. "Litauer in der litauischen Geschichte finden": Konstruktion des Nati- onalen unter Smetona}

Smetonas Politik gegenüber anderen Ethnien richtete sich nach dem bereits 1912 erwähnten Prinzip des ethnolinguistischen Nationalismus: „All Lithuanian, but little national“. ${ }^{20}$ Zur Stärkung des nationalen Bewusstseins sei die Förderung der litauischen Sprache und die Loyalität zur ethnischen Tradition essenziell, nicht die ethnische Herkunft. Die nicht-litauischen Ethnien wie Juden, Deutsche oder Polen wurden toleriert und die jeweiligen Schulen gefördert, solange sie die Hegemonie des Litauischen nicht herausforderten. Smetonas Linie bestand somit nicht in der ethnischen, sondern in der kulturellen Purifikation. Als erstes sollte jedoch die nationale litauische Kultur „konstruiert“ - das heißt vor allem de-polonisiert - und gefestigt werden. Das Hauptziel der ethnonationalen Kulturpolitik Smetonas bestand in der Entfernung der Entlehnungen aus dem Polnischen in Kultur und Sprache.

Welches waren die geschichtspolitische Ziele Smetonas, und welche Motive dienten der Konstruktion des nationalen Gedächtnisses Litauens in der Zwischenkriegszeit? Es ist zweifellos Smetona, auf den die Entdeckung und Etablierung des litauischen Nationalhelden Nr. 1 zurückgeht. Der Großfürst Vytautas aus dem 14. 15. Jahrhundert eignete sich hervorragend als Symbol der nationalen Konsolidierung: er soll mit „eiserner Hand“ regiert haben, litt unter polnischen Manipulationen (es war die polnische Szlachta, die seine Krönung zum König verhinder-

18 Zit. nach Alfonsa Eidintas, Antanas Smetona and His Lithuania. From the National Liberation Movemento to an Authoritarian Regime (1893-1940), Leiden/Boston 2015, S. 139.

${ }^{19}$ Hier ist die Frage nach den Verbindungen zum italienischen Faschismus interessant. Tatsächlich hielten die „Tautininkai“ die faschistischen Bewegungen in Italien, Ungarn sowie die militärischen Staatsstreiche in Bulgarien und Spanien für logische Folgen der Volkserhebungen gegen den Parlamentarismus; vgl. ebenda, S. 162. Smetona selbst distanzierte sich vom italienischen Faschismus („wesensfremd“ für Litauen) und vom deutschen Nationalsozialismus; vgl. Aleksandras Merkelis, Antanas Smetona. Jo visuomeninè, kultūrinè ir politinè veikla, New York 1964, S. 178.

${ }^{20}$ Zit. nach Eidintas, Antanas Smetona, S. 262. 
te), er erweiterte Litauen „von der Ostsee- bis zur Schwarzmeerküste“ und förderte die katholische Kirche. ${ }^{21} 1930$ wurde daher der 500. Todestag von Vytautas (13501430) landesweit mit großem Pomp begangen, überall in Litauen wurden Denkmäler zu seinen Ehren eingeweiht.

Den Höhepunkt der Jubiläumsfeierlichkeiten bildete der Beschluss zur Gründung des Nationalmuseums zu seinen Ehren in Kaunas, der provisorischen Hauptstadt Litauens. Das nationale Pantheon sollte den Namen „Vytautas-derGroße“ im Titel tragen. In einer feierlichen Zeremonie wurde im November 1930 der Grundstein für das Nationalmuseum gelegt und der Erinnerungsort in einem quasi national-sakramentalen Akt „geweiht“: Ins Fundament wurde Erde von den national-litauischen Schicksalsorten geschüttet - dem Gediminas-Berg, dem Rasos-Friedhof und von Schauplätzen der militärischen Auseinandersetzung um Vilnius. Am 16. Februar 1936, am Tag der nationalen Unabhängigkeit, wurde das Museum Vytautas-des-Großen offiziell eröffnet. Den Charakter der litauischen Walhalla vermittelte die Vytautas-Kapelle, die sich dem Besucher unmittelbar hinter dem Museumseingang öffnete. Das Museum portraitierte alle litauischen Herrscher bis 1794 (von Rimgaudas bis Poniatowski) und dann wieder ab 1918: Für den zeitlichen Abschnitt der Zarenzeit wurde die Stelle mit einem Trauerkranz gefüllt. ${ }^{22}$

Den roten Faden des litauischen historischen Narrativs in der Smetona-Zeit sollte die Losung „Litauen in der litauischen Geschichte finden“ darstellen, welche auf die historiografische Schule von Adolfas Šapoka zurückgeht. Spätestens seit dem Jahr 1936, als der Historiker Šapoka zusammen mit vier weiteren Kollegen seine paradigmatische Synthese „Geschichte Litauens“ herausgab, lässt sich für das Litauen der Zwischenkriegszeit von einem konsolidierten historischen Narrativ sprechen. ${ }^{23}$ Diese historische Meistererzählung entwickelte ein selektives Modell der litauischen Geschichte, in der der Nation als historischer Kategorie ein exkludierender und defensiver Charakter zugewiesen wurde. Das Ziel dieser Bemühungen war es, die litauische Geschichte vom Einfluss anderer Historiografien zu „säubern“ beziehungsweise zu retten. ${ }^{24}$ Nicht die Gemeinsamkeiten oder Verflechtungen wurden thematisiert, sondern Konfrontationen. Als Leitlinie der Erzählung diente das Motiv der litauischen Staatlichkeit, ihrer Entwicklung in der Vergangenheit und der steten Bedrohung ihrer Existenz. Litauen erhielt in diesem Geschichtsbild für die Epochen der nationalen Unselbständigkeit, also von der Gründung der Polnisch-Litauischen Union 1569 bis zum Ende des Ersten Weltkriegs 1918, die Rolle einer „belagerten Festung“, die von drei „historischen Feinden“ umzingelt war, nämlich den Deutschen, Russen und Polen. Auch hat

\footnotetext{
${ }^{21}$ Zit. nach ebenda, S. 263.

${ }^{22}$ Vgl. Nastazija Keršytè, Lietuvos muziejai iki 1940 metų. Lietuvos muzieju raida XVI-XX amžiaus ketvirtajame dešimtmetyje, Vilnius 2003.

${ }^{23}$ Vgl. Adolfas Šapoka (Hrsg.), Lietuvos Istorija. Kaunas 1936. Die englischsprachige Ausgabe ders., Lithuania Through the Ages, Toronto 1948, ist online einsehbar: www.partizanai.org/ index.php/red-a-sapoka-lietuvos-istorija [13.4.2016].

${ }^{24}$ Vgl. Aurimas Švedas, Matricos nelaisvejje. Sovietmečio lietuviu istoriografija (1944-1989), Vilnius 2009, S. 184.
} 
Šapoka maßgeblich zur Verankerung des Großfürsten Vytautas als Kultfigur in der litauischen Geschichte beigetragen.

Neben der Manifestation historisch-kultureller Wurzeln der litauischen Nation förderte Smetona die Symbolik des modernen nationalen Gefallenenkults. In einer feierlichen staatlichen Zeremonie wurden 1934 in Kaunas an der Gedenkanlage zu Ehren der Gefallenen der Freiheitskriege die Gebeine eines unbekannten Soldaten (gefallen in den Kämpfen um Vilnius) beigesetzt. ${ }^{25}$ Überhaupt entwickelte sich der Vorplatz vor dem Vytautas-der-Große-Museum zum nationalen Heiligtum, da es in bemerkenswerter Dichte alles Litauische verband: das Grab des Unbekannten Soldaten, die Freiheitsstatue, die Krypta für die Gefallenen für die Freiheit und mehrere Denkmäler für die nationalen „Erwecker“. Am 23. November (Tag der Gründung der litauischen Armee) wurde der Platz alljährlich zum Schauplatz der gigantischen Nationalfeierlichkeiten.

In der intensiven Forderung des „nationalen Neuanfangs“ und Kults betonte Smetona die exklusiven Merkmale litauischer „Identität“. Es ging ihm um eine Definition des Litauischen ex negativo - Litauer seien keine Polen, keine Russen, keine Juden, keine Belorussen. Dafür popularisierte er stark die bäuerliche Folklore, die - im Gegensatz zur polnischen Adelskultur - als Ausdruck der „Seele der Nation" wahrgenommen wurde. ${ }^{26}$

Es ist nicht überraschend, dass die Zwischenkriegszeit nach dem Ende des Zweiten Weltkriegs und der Wiederetablierung der Sowjetmacht in Litauen in der sowjetischen Historiografie auf die Smetona-Zeit reduziert wurde, die offiziell als „faschistisches Regime“ bezeichnet wurde. ${ }^{27}$ Die Funktionalisierung des Faschismus-Begriffs durch die litauischen Kommunisten bestand darin, sich positiv von der Smetona-Zeit abzugrenzen und die eigenen Leidenswege als Kommunisten etwa Antanas Sniečkus und Motejus Šumauskas als politische Häftlinge - während der autoritären Diktatur zu betonen. Von der ebenso starken negativen Konnotation betroffen waren die „bürgerlichen Nationalisten“, die während der deutschen Besatzung Litauens (1941-1944) mit den Deutschen kollaboriert und bei der Repression und Ermordung von Werktätigen mitgewirkt hatten. Das Feindbild „bürgerlicher Nationalist“ wurde dem des „Faschisten“ gleichgesetzt, und die Befreiung Litauens von der deutschen Okkupation als nationale Rettung vor dem ewigen deutschen „Drang nach Osten“ beschrieben. ${ }^{28}$ Der Sieg über den Faschismus sollte somit den erneuten Kampf gegen die „Faschisten“ der Zwischenkriegszeit legitimieren, und auch auf der Ebene der Feindbegriffe nutzte die Propaganda den stigmatisierenden Begriff Faschismus, um alle Spuren der nationalen, auf die eigene Staatlichkeit bezogenen Kultur aus der Zwischenkriegszeit auszu-radieren. Die historiografische Grundlage für den Begriff Faschismus legte Israelis

\footnotetext{
${ }^{25}$ Vgl. Darius Staliūnas, Der Kult des Unbekannten Soldaten in Litauen, in: Nordost-Archiv 17 (2008), S. 248-266.

${ }^{26}$ Vgl. Rasa Čepaitienè, Laikas ir akmenys. Kultūros paveldo sampratos moderniojoje Lietuvoje, Vilnius 2005.

${ }^{27}$ Vgl. Ekaterina Makhotina, Erinnerungen an den Krieg, Krieg der Erinnerungen. Litauen und der Zweite Weltkrieg, Göttingen 2017, S. 176.

${ }^{28}$ Vgl. ebenda, S. 90-115.
} 
Lempertas mit seiner Monografie „Das faschistische Regime in Litauen“, ${ }^{29}$ und bis 1990 sollte an dieser Definition nicht gerüttelt werden.

Die Entfernung der Symbole der nationalen „Erweckung“vom Vorplatz des Nationalmuseums - vor allem des Grabs des Unbekannten Soldaten und der Büsten der Kulturschaffenden und Militärs der Zwischenkriegszeit - war die logische Folge dieser Politik, das Nationalmuseum selbst wurde zum Staatlichen Historischen Museum. Zugleich hielt die litauische kommunistische Propaganda den bereits etablierten Vytautas-Kult aufrecht und ergänzte ihn mit dem Motiv der historisch verwurzelten Völkerverständigung, wofür die Schlacht von Grunwald (Tannenberg) von 1410 stehen sollte. Damals und im Zweiten Weltkrieg hätten Litauer zusammen mit den „Slawen“ den deutschen Angreifern erfolgreich Widerstand geleistet. Ähnlich pompös wie den runden Todestag von Vytautas feierte Litauen im Jahr 1960 „550 Jahre Grunwaldschlacht““.

In der propagierten Kultur-Formel der litauischen Kommunisten „national in der Form, sozialistisch im Inhalt", sollte das ferne goldene Mittelalter eben die nationale Form darstellen. Die Erinnerungsorte des litauischen Gründungsmythos wie die Gediminas-Burg in Vilnius wurden in die offiziellen Rituale eingebunden. Die Sowjetmacht feierte vor der Burgkulisse das litauische Vilnius und versuchte hiermit ihre Legitimität bei der Bevölkerung zu stärken. ${ }^{31}$ Aus dem Korpus des Nationalen wurde die bäuerliche Kultur - die Folklorekunst - als echte nationale litauische Kultur definiert, während die Staatssymbole des unabhängigen Litauen (Hymne, Flagge) verboten wurden.

\section{Rückkehr zur historischen Selbstgenügsamkeit: Die Smetona-Zeit und das unabhängige Litauen}

Im Zuge der von Michail Gorbačev eingeschlagen Glasnost'-Politik suchten Litauen wie auch andere sowjetische Republiken nach einem nationalen Weg der Befreiung aus dem sowjetischen System. Die Umwertung der Geschichte spielte dabei eine zentrale Rolle. Die Bewegung zur Unterstützung der Perestroika - Sajudis -, die sich im Juni 1988 gründete, propagierte die Befreiung vom sowjetischen System als nationale Angelegenheit. Gefordert wurde die Rückkehr zur „historischen Wahrheit“. Wieder einmal griff der populäre Diskurs die Figur des Großfürsten Vytautas heraus: Nun sollte der mittelalterliche Held zum ersten „AntiKommunisten Litauens“ erklärt werden. ${ }^{32}$ Zur Grundlage der „Gegen-Geschichte“ wurde die massenhafte Neuauflage des Werks von Alfonsas Šapoka, was zur Wiederbelebung des Narrativs der belagerten Festung beitrug und eine historische

\footnotetext{
${ }^{29}$ Vgl. Israelis Lempertas, Fašistinis režimas Lietuvoje, Vilnius 1975.

${ }^{30}$ Vgl. Makhotina, Erinnerungen, S. 113-115.

${ }^{31}$ Vilnius wurde nach der Besetzung ostpolnischer Gebiete durch die UdSSR durch diese am 10.10.1939 an Litauen übereignet, nach dem Anschluss an die Sowjetunion am 3.8.1940 wurde es Hauptstadt der litauischen Sowjetrepublik.

${ }^{32} \mathrm{Zu}$ Metamorphosen von Vytautas als Erinnerungsfigur vgl. Neringa Klumbyte, Ethnographic Note on „Nation“. Narratives and Symbols of the Early Post-socialist Nationalism in Lithuania, in: Dialectical Anthropology 27 (2003), S. 279-295, hier 281.
} 
Selbstbezogenheit stiftete. ${ }^{33}$ Die dazugekommenen Werke der litauischen Diaspora unterstrichen das Selbstbild einer leidenden und kämpfenden Nation während der sowjetischen Okkupation. ${ }^{34}$

Die Umwertung der Geschichte betraf zunächst die Zeit der ersten Litauischen Republik 1918 bis 1940. Die Neudeutung erfolgte auf der höchsten Ebene durch den neuen Chef der Kommunistischen Partei Litauens (KPL) Algirdas Brazauskas am 16. Dezember 1988, dem 70. Jahrestag der Gründung der KPL. Die KPL habe, so Brazauskas, „die Losung der Schaffung eines unabhängigen litauischen Staats nicht erhoben“ und damit die "Sehnsucht breiter Bevölkerungsschichten auf einen eigenständigen litauischen Staat enttäuscht“. ${ }^{35}$ Die Konkurrenz der Gründungsdaten der litauischen Republik 1918 (16. Februar) und der Gründung der KPL (16. Dezember) wurde zu Gunsten des ersteren entschieden. Die Rede Brazauskas' rehabilitierte den Tag der ers-ten litauischen Unabhängigkeit und machte seine feierliche Begehung 1989 möglich. Es versteht sich von selbst, dass die Diktatur Smetonas das Prädikat „faschistisch“ verloren hat und grundlegend rehabilitiert wurde. ${ }^{36}$ Litauische Straßen erhielten seinen Namen, so wurde die Gogol'-Straße in Vilnius in Smetona-Straße umbenannt.

Einen Monat vor der Unabhängigkeitserklärung Litauens, also im Februar 1990, wurde die erste symbolpolitische Regelung beschlossen, nämlich das Gesetz zu den Feiertagen. Mit ihm wurde in Erinnerung an die Staatsgründung 1918 der 16. Februar als Feiertag eingeführt. ${ }^{37}$

Am 11. März 1990 deklarierte der Oberste Sowjet Litauens die Re-Etablierung des litauischen Staats mit der Verfassung von 1938, die jedoch suspendiert und durch eine provisorische ersetzt wurde. Dass im heutigen Litauen zwei Unabhängigkeitsdaten - das von 1918 und das von 1990 - gefeiert werden, zeugt vom hohen Stellenwert der Staatssouveränität im geschichtspolitischen Diskurs. Zugleich haben die rechts-nationalen Kräfte mit ihren autoritären Tendenzen und isolationistischen Visionen im heutigen Litauen an politischem Gewicht verloren. Bereits in den 1990er Jahren konnte die Neuauflage der Tautininkai nur wenig politischen Einfluss ausüben, heute besteht sie als „Fraktion der Nationalen“innerhalb der einflussreichen konservativen Partei Union des Vaterlands, die einen Kurs auf Integration in den Westen bei Wahrung der nationalen Identität verfolgt.

Während also die LTS nur wenig politischen Einfluss im heutigen Litauen hat, bleibt das von Smetona geförderte historische Narrativ der defensiven Eigenstaatlichkeit hingegen anschlussfähig. Die „historische Selbstgenügsamkeit“, die, dem

${ }^{33}$ Noch 2005 wurde Šapoka zu den zehn wichtigsten Autoren Litauens gezählt; vgl. Delfi vom 13.5.2005: „Dešimt svarbiausiu lietuviu autoriu“; www.delfi.lt/archive/desimt-svarbiausiulietuviu-autoriu.d?id=6670411 [13.4.2016].

${ }^{34}$ Vgl. Dovilè Budrytė, „We Call It Genocide“. Soviet Deportations and Repression in the Memory of Lithuanians, in: Robert S. Frey (Hrsg.), The Genocidal Temptation. Auschwitz, Hiroshima, Rwanda, and Beyond, Dallas u. a. 2004, S. 79-100, hier S. 93.

35 Tiesa vom 17.12.1988: „Revoliucines kovos, kurijamo darbo ir persitvarkymo keliu“.

${ }^{36}$ Vgl. die Darstellung der Diktatur bei Eidintas, Antanas Smetona, in der der Diktatur viel Verständnis entgegengebracht wird.

${ }^{37}$ Vgl. Makhotina, Erinnerungen, S. 247. 
Šapoka-Konzept folgend, nach „Litauen in der litauischen Geschichte“ sucht, gipfelte in dem kostspieligen Wiederaufbauprojekt des Großfürsterlichen Palasts, zum „Millennium“ Litauens (2009). ${ }^{38}$ Weitere Beispiele der Lituanisierung litauischer Geschichte finden sich im Programm des litauischen Millenniums ${ }^{39}$ und in der Konzeption des litauischen Nationalmuseums in Vilnius: Die mythische Zeit des hochmittelalterlichen Großfürstentums ist ein wichtiger Bezugspunkt litauischer Geschichtspolitik von heute. Auch in der Politik der Einschränkung der Rechte der polnischsprachige Litauer - die Verwendung polnischer Schreibweisen von Straßen- und Eigennamen ist beschränkt - lassen sich Spuren der kulturellen De-Polonisierung unter Smetona erkennen. ${ }^{40}$

Die Parallelen zwischen dem Smetona-Litauen und der heutigen Zeit bestehen also in Bezug auf die Geschichtskultur, in der das „genuin“ Litauische und das Mittelalter als nationale Blütezeit hervorgehoben werden. Die Einflüsse anderer nationalen Gruppen - und die Kultur während der Zeit des Sozialismus, die als „Fremdherrschaft“ bezeichnet wurde - sollen dagegen ausgegrenzt werden.

\section{Fazit}

Obwohl Smetonas Name also nur wenig mit demokratischen Erfolgen Litauens in Verbindung gebracht werden kann, wird sein Handeln 1926 als Antwort auf die Ineffektivität des Parlaments (Seima) gerechtfertigt ${ }^{41}$ und er selbst als „Lituanisierer Litauens“" positiv gedeutet. Dass er eine autoritäre Diktatur einführte und protofaschistische Zirkel und nationalistische Losungen wie „Litauen den Litauern“ gedeihen ließ, ${ }^{42}$ geht häufig in Apologetik unter. Smetona habe in der Zwischenkriegszeit ein starkes nationales Bewusstsein geschaffen, das sich gegen die „Sowjetisierung" behaupten konnte, so die Deutung. ${ }^{43}$ Die während der Smetona-Zeit sich entwickelnde Idee der nationalen Staatlichkeit habe die Zeit der Okkupation zu überstehen geholfen und stelle eine gewisse Rechtfertigung der Diktatur dar.

\footnotetext{
${ }^{38}$ Die Entstehung der litauischen Nation wird auf das Jahr 1009 zurückgeführt, als die Bezeichnung „Litua“ zum ersten Mal in den Quedlinburger Annalen erwähnt wurde.

${ }^{39}$ Die im Kulturprogramm „Tukštantmeties Lietuvos“ verwendeten Schlüsselbegriffe wie Nation und Freiheit wurden im massenmedialen Geschichtsdiskurs oft reproduziert und verbanden sich mit dem Symbol des „Vytis“ (Ritter zu Pferd) und dem Slogan: „Wer nicht bereit ist, für die Freiheit zu sterben, der hat die Freiheit nicht verdient“; zit. nach Martin Schulze Wessel/Ekaterina Makhotina, Einleitung, in: Martin Schulze Wessel/Irene Götz/Ekaterina Makhotina (Hrsg.), Vilnius. Geschichte und Gedächtnis einer Stadt zwischen den Kulturen, Frankfurt a. M. /New York 2010, S. 9-24, hier S. 10 f.

402009 entschied das Landesverfassungsgericht gegen die Verwendung der polnischen $\mathrm{Na}-$ mens-Schreibweise; vgl. Michał Olszewski, Analyse. Polen und Litauen - eine komplizierte Nachbarschaft, 20.3.2013; online: www.bpb.de/internationales/europa/polen/156906/ analyse-polen-und-litauen-eine-komplizierte-nachbarschaft? $\mathrm{p}=$ all [18.2018].

${ }^{41}$ So schreibt sein Biograf Eidintas, Antanas Smetona, S. 440: „Taking the government from the coup leaders, he violated the articles and democratic order of Lithuania's constitution of 1922, rejecting the parliamentary system, since he saw only bad and no essential work in the Seimas."

42 Zit. nach ders. u. a., Geschichte Litauens, S. 191.

${ }^{43}$ Vgl. ders., Antanas Smetona, S. 444.
} 
Nicht zuletzt Smetonas Beharren auf Vilnius als Litauens Hauptstadt lässt ihn als einen starken nationalen Mobilisierer und Propagandisten erscheinen. „Litauen war [...] endgültig litauisch geworden“, konstatiert die im Auftrag des Ministeriums für Auswärtige Angelegenheiten Litauens erstellte Überblicksdarstellung „Geschichte Litauens“. ${ }^{44}$ Ein anderer Autor bescheinigt Smetonas Litauen einen "großen kulturellen Sprung“. ${ }^{45}$ So wird die autoritäre Diktatur romantisiert und mythologisiert - was auch im post-sowjetischen Litauen zur Artikulierung der Forderung nach einer starken Hand in der politischen Führung führt. ${ }^{46}$

${ }^{44}$ Ders. u. a., Geschichte Litauens, S. 193.

45 Ders., Antanas Smetona, S. 260.

${ }^{46}$ So z. B. die Umfragen 2010, bei der 71 Prozent der Litauer sich für eine stärkere präsidentielle Macht aussprachen; vgl. Delfi vom 17.5.2010: „D.Grybauskaitei demonstruojant kieta ranka, gyventojai vis dar nori stiprinti prezidento galias“; www.delfi.lt/news/daily/lithuania/dgrybauskaitei-demonstruojant-kieta-ranka-gyventojai-vis-dar-nori-stiprinti-prezidentogalias.d?id=32358037 [18.1.2018]. 